\title{
EXPERIMENTAL AND NUMERICAL ANALYSIS OF A FRCM REINFORCED PARABOLIC TUFF BARREL VAULT
}

\author{
ANNA CASTELLANO ${ }^{1}$, JACOPO SCACCO ${ }^{2}$, AGUINALDO FRADDOSIO ${ }^{3 *}$, \\ GABRIELE MILANI ${ }^{2}$, MARIO DANIELE PICCIONI ${ }^{3}$ \\ ${ }^{1}$ Department of Mechanics, Mathematics and Management (DMMM) \\ Polytechnic University of Bari \\ via Re David, 70125 Bari, Italy \\ e-mail: anna.castellano@poliba.it,www.dmmm.poliba.it \\ ${ }^{2}$ Department of Architecture, Built environment and Construction engineering ABC \\ Politecnico di Milano \\ Piazza Leonardo da Vinci 32, 20133, Milan, Italy \\ e-mail: jacopo.scacco@polimi.it, gabriele.milani@polimi.it,www.abc.polimi.it/ \\ ${ }^{3}$ Department of Civil Engineering Sciences and Architecture (DICAR) \\ Polytechnic University of Bari \\ via Re David, 70125 Bari, Italy \\ e-mail: aguinaldo.fraddosio@poliba.it, (*corresponding author)mariodaniele.piccioni@poliba.it, \\ www.dipartimentoicar.it
}

Keywords: Historical Construction, Masonry, Vaults, Fiber Reinforced Cementitious Matrix (FRCM), Experimental mechanics, Micro-modeling.

\begin{abstract}
An experimental and numerical analysis of the structural behaviour of a barrel tuff masonry vault strengthened by a Fiber Reinforced Cementitious Matrix (FRCM) reinforcement system it is proposed. The geometry and the materials of the vault are representative of some historical constructions in Apulia (Italy). The vault, under the action of the self-weight and of a distributed load representative of the infill, has been first damaged by differential settlement of abutments, and then repaired and strengthened by FRCM composites. Finally the structure has been subjected to a increasing concentrated load on the extrados. A 3D heterogeneous FE Abaqus numerical model describing the above mentioned experimental conditions is carried out in order to reproduce the response of the FRCM reinforced vault. The obtained experimental and numerical results allows for discussing the structural behaviour of the reinforced vault, and then the effectiveness of the employed reinforcement.
\end{abstract}

\section{INTRODUCTION}

The integrity of barrel masonry vaults plays a crucial role in the structural behavior of construction of the architectural heritage like palaces, churches, cloisters and castles. Anyway, settlements of abutments of the vault, for example induced by foundations differential displacement often induce considerable damage [1].

For historical constructions, the presence of damage states induced by foundations 
settlements is often the norm rather than the exception. Whereas these damage states can be irrelevant in term structural capacity of withstanding ordinary gravitational loads, they can significantly undermine the load carrying capacity against exceptional loads, first and foremost seismic loads. Thus, it arises the necessity of suitable strengthening interventions, capable of restoring or eventually increasing the structural capacity of the undamaged construction.

In this vein, Fiber Reinforced Cementitious Matrix (FRCM) composites have gained an increasing interest as material for the reinforcement of historical masonry constructions. This is due mostly to the high compatibility with historical masonries, both from the technological and the structural point of view [2], and for the possibility of making diffuse reinforcement interventions.

The study of the structural behavior FRCM reinforced masonry construction is even now an open research issue, especially in the case of curved structures like arches, vaults and domes. Indeed, in the literature there are still too little numerical (see, e.g., [3]) and experimental papers [4-9] on this subject.

The experimental and numerical work here proposed aims at studying the effectiveness of a Fiber Reinforced Cementitious Matrix (FRCM) reinforcement system of a barrel masonry vault in terms of the load carrying capacity.

The geometry and the materials of the masonry vault resemble a typology of masonry vaults common in the historical centers of Apulia (Italy). In particular, a polycentric near parabolic vault was constructed by using Apulian tuff ashlars put together with a lime-cement mortar.

For what concerns weight, to a distributed
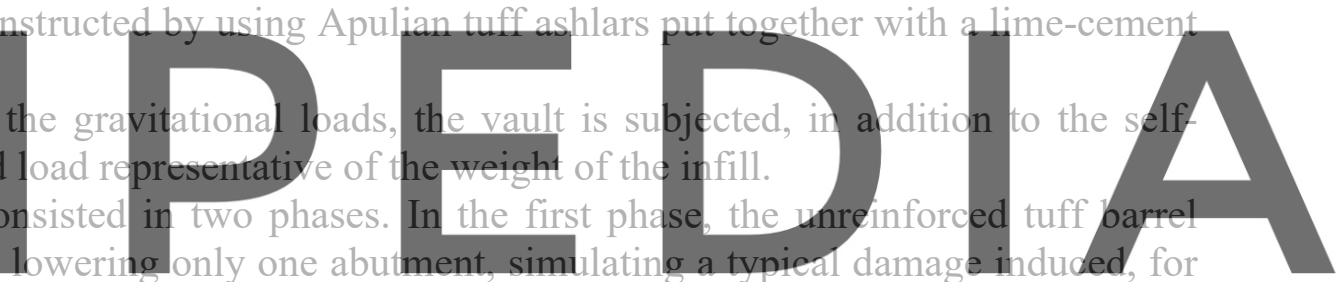

vault was damaged by lowering only

Register for Pree atdateds reinforced by a FRCM system composed by a fiber-reinforced mortar embedding a basalt fiber net. At this point, the second phase of the experiment consisted in applying a increasing concentrated load to the extrados of the vault along a generatrix in order to study the load carrying capacity of the reinforced vault, and then the effectiveness of the reinforcement.

The experiment, performed on a full-scale vault, required a quite complex experimental setup ad hoc designed [7,8]. In both tests, the masonry vault was continuously monitored through of several sensors placed in appropriate points of the intrados and extrados of the structure. In the second phase, discussed in the present paper, the load was gradually increased by 8 slow loading-unloading cycles. The reprocessing of the experimental data gives very accurate quantitative information on the structural response of the reinforced vault.

A 3D heterogeneous FE Abaqus numerical model reproducing the experimental conditions previously discussed is carried out in order to reproduce the second phase of the experiment. In the FE approach adopted, stones, mortar joints and cementitious matrix are assumed obeying a Concrete Damage Plasticity material model, with softening in both tension and compression, whereas equivalent elasto-damaging trusses are utilized for the fiber net. The FE model is calibrated on the results of experimental tests on the materials used for the vault and for the reinforcement. The numerical results fit with sufficient accuracy the experimental 
outcomes, providing a useful reference for future application of FRCM strengthening technique on curved masonry structures.

\section{TUFF BARRELL VAULT: GEOMETRY AND MATERIALS}

The full-scale barrel masonry vault under test was designed specifically to reproduce both the geometry and the materials of some vaults widespread in historical cities of Apulia (Italy).

In particular, for what concerns the geometry, the vault has a raised, polycentric profile, whose shape is more similar to the parabola than to the circumference [7-7]. The span is 346 $\mathrm{cm}$ and the rise $120 \mathrm{~cm}$ (Fig. 1-2). For what concerns the materials, the voussoirs were made by cutting blocks of the so-called Apulian tuff, coming from the quarries of Gravina in Puglia. Moreover, for the construction of the vault a lime-cement mortar with low mechanical properties very similar to the properties of mortars used in rural tuff constructions was employed.

The vault was built at Laboratorio Ufficiale Prove Materiali "M. Salvati" of Politecnico di Bari, where experimental tests were carried out. The two supports of the vault are made by steel beams: one support is fixed, while the other can be moved by a hydraulic jack, allowing for controlled vertical displacements of one of the abutments of the vault. Two additional steel beams placed on the top lateral shoulders of the vault give further constraints, avoiding rigid rotations of the whole structure $[7,8]$.
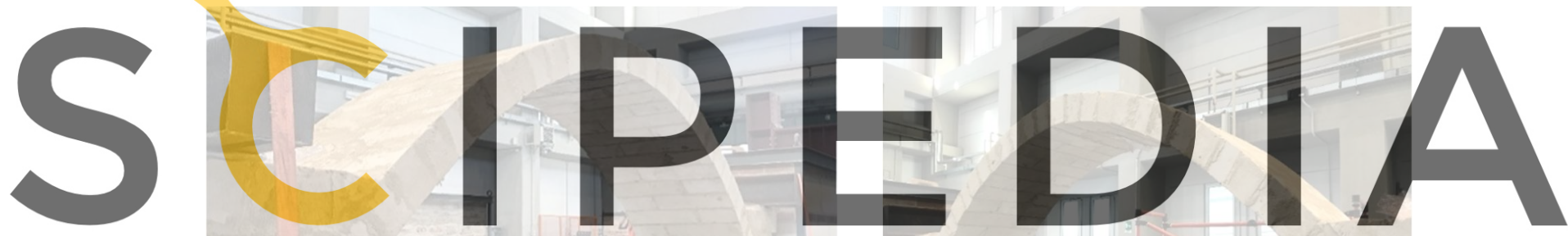

Register for free at https//www.scipedia.com to download the version without the watermark
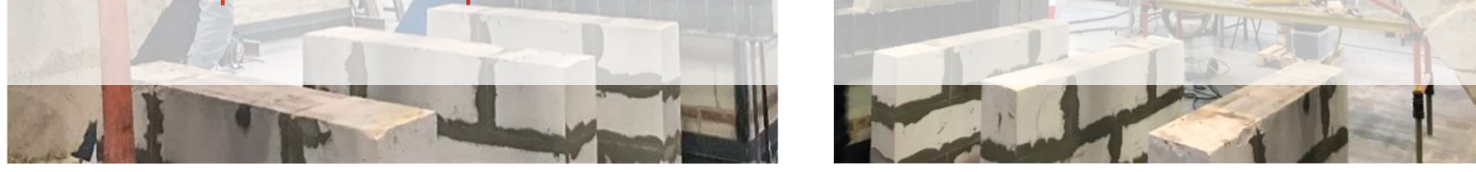

Figure 1: Tuff Barrell Masonry Vault (front)

Figure 2: Tuff Barrell Masonry Vault (back)

The mechanical properties of materials have been determined by mechanical tests in accordance with UNI standards. In particular, according to UNI EN 772-1:2011 and UNI EN 1926:2007 standard compression tests were performed on six cubic tuff samples having nominal dimensions of $430 \mathrm{~mm}$ x $240 \mathrm{~mm} \times 150 \mathrm{~mm}$ and average mass density $1400 \mathrm{~kg} / \mathrm{m}^{3}$. The samples were tested using a Metro Com universal testing machine with load capacity of $600 \mathrm{kN}$. From the experimental results, it was possible to determine the average compressive strength $\mathrm{f}_{\mathrm{bm}}=2.25 \mathrm{MPa}$, the characteristic compressive strength $\mathrm{f}_{\mathrm{bk}}=1.87 \mathrm{MPa}$ and the average Young modulus $\mathrm{E}_{\mathrm{m}}=637.39 \mathrm{MPa}$ of the bricks. Moreover, according to UNI EN 1015-11:2007 six prismatic samples of the mortar with nominal dimensions of $14 \mathrm{~mm} \times 14$ $\mathrm{mm} \times 160 \mathrm{~mm}$ and average mass density $1883.98 \mathrm{~kg} / \mathrm{m}^{3}$ were prepared during the construction of the vault. After 28 days of curing these samples were subjected to flexural 
tests (three-point bending tests) and compression tests by using an INSTRON 5689 universal testing machine with load capacity of $50 \mathrm{kN}$. Then, the flexural strength $\mathrm{f}_{\mathrm{mf}}=1.91 \mathrm{MPa}$, the compressive strength $\mathrm{f}_{\mathrm{mc}}=8.94 \mathrm{MPa}$ and the average Young modulus $\mathrm{E}_{\mathrm{m}}=6902.27 \mathrm{MPa}$ of the mortar has been determined.

The FRCM reinforcement consisted in a basalt fiber mesh $(6 \mathrm{~mm} \times 6 \mathrm{~mm})$ embedded in a cement mortar. The basalt fiber net has a tensile strength $\mathrm{f}_{\mathrm{tB}}=60 \mathrm{kN} / \mathrm{m}$ and a Young modulus $\mathrm{E}_{\mathrm{B}}=89000 \mathrm{MPa}$.

\section{EXPERIMENTAL TESTS AND RESULTS}

\subsection{Setup}

A quite complex experimental setup was designed and built, in order to control both the vertical displacement of one of the two supports and the concentrated load on a generating line of the extrados of the vault. The complexity is related also to the dimension of the vault, that is a full-scale structure.

After the construction of the vault, 40 sandbags (with total weight $840 \mathrm{~kg}$ ) were placed on the top of the vault in order to simulate the infill load (Fig 3).
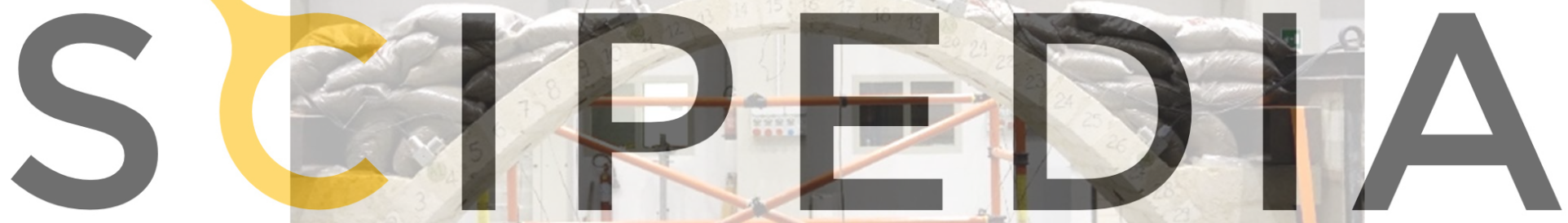

Register for free at https//www.scipedia.com to download the version without the watermark

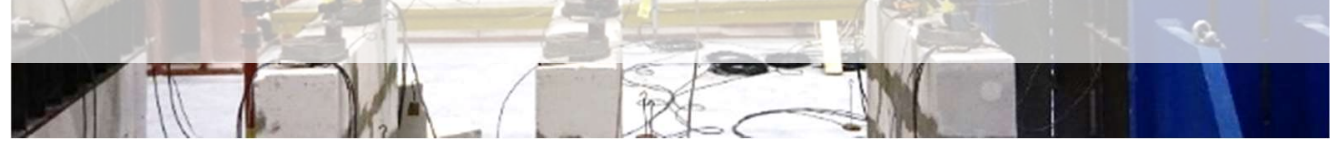

Figure 3: The masonry vault with sandbags in order to simulate the infill load

During both tests, the mechanical response of the vault continuously monitored through different sensors (Fig. 4) placed in suitable points of the vault and on supports [7,8]:

- 9 electrical strain gauges applied to the intrados of the vault along the middle axis (SI1, ..., SI9);

- 7 electrical strain gauges applied to the extrados of the vault along the middle axis (SE1, ..., SE7);

- 8 pairs of monoaxial accelerometers applied to the extrados of the vault, with measuring directions oriented tangent and orthogonal to the vault, respectively, and placed symmetrically with respect to the middle axis of the vault (A1, ., A8);

- 6 potentiometric displacement transducers connected by 6 plumb-lines to suitable 
points of the intrados of the vault $(\mathrm{P} 1, \ldots, \mathrm{P} 6)$;

- 2 LVDT displacement transducers (LVDT1, LVDT2) applied on the support steel beam capable of vertical displacements controlled by the jack.

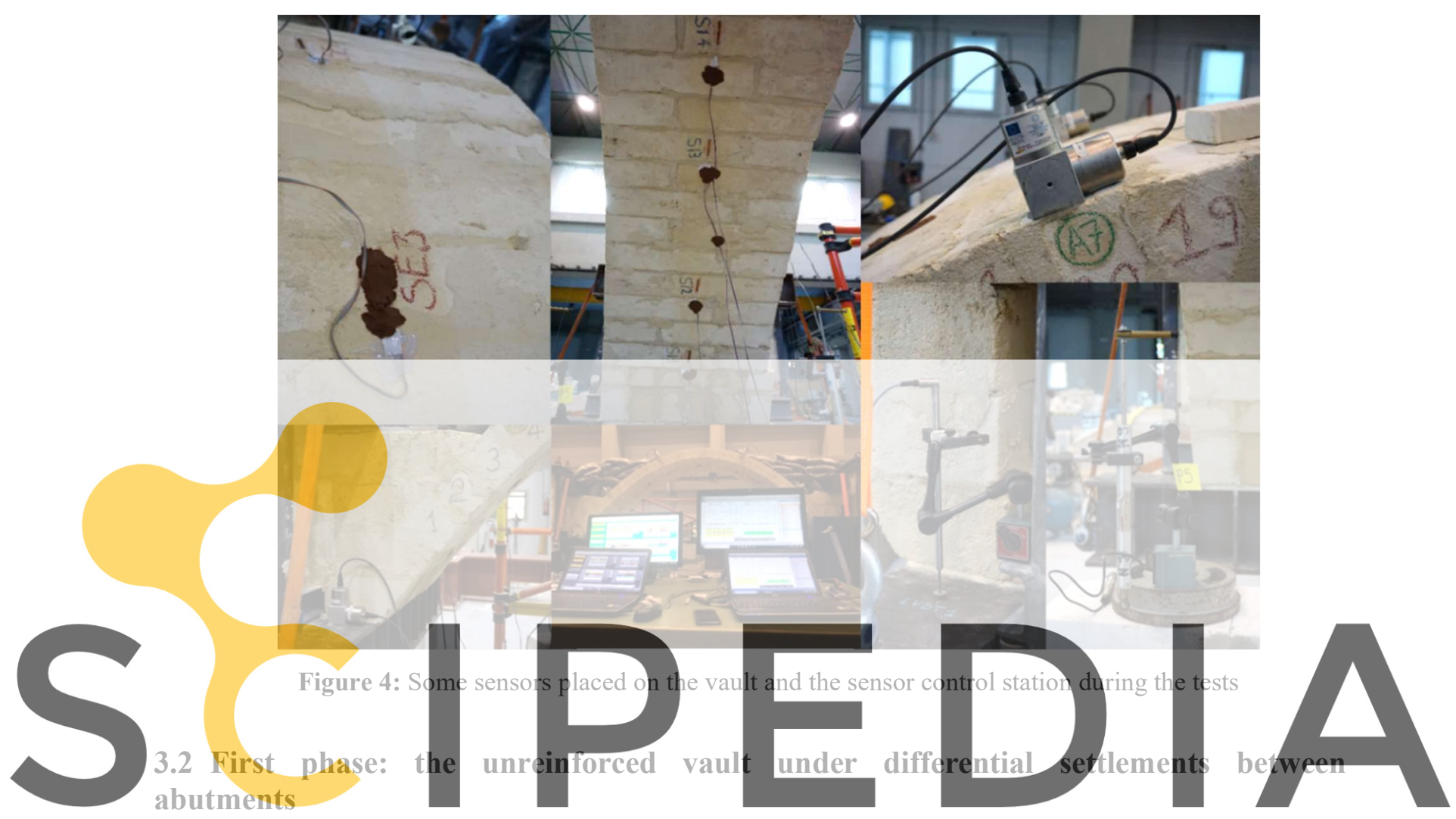

Two different experimental campaigns were performed; in the first, the unreinforced vault

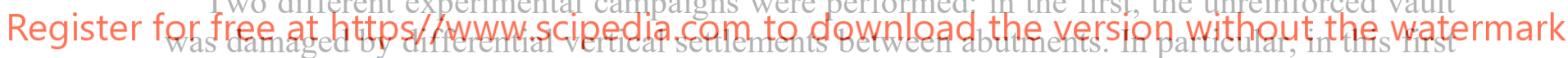

phase a hydraulic jack placed under one of the supports of the vault allowing differential vertical settiements between abutments. The test was carried out in displacement control by gradually applying the differential settlements through subsequent increments. At the end of each step, a visual inspection was performed in order to evaluate the opening of cracks; moreover, the dynamic response of the vault under white noise excitation was acquired.

The test was interrupted when the formed cracks transformed the vault in a statically determined structure, thus capable of adapting to differential settlements by rigid body rotations. This happened at the 11th settlement step, corresponding to a relative vertical displacement between abutments of about $17 \mathrm{~mm}$.

The cracking hinges formed in positions compatible to those typical of the collapse mechanism of a circular arch under vertical support settlements without rotations of the abutments (mechanism III in [10]).

In particular, an intrados cracking hinge formed in correspondence of the joint between voussoirs 23 and 24, and two extrados cracking hinges appeared in correspondence of the joint between voussoirs 14 and 15, and of voussoirs 11 and 10, respectively (Fig. 5).

According to the observations in [11], the slight differences from the cited mechanism in 
[10] were likely ascribable to the shape of the vault (that have a parabolic profile rather than circular), by the different embrace angle and by the different thickness to radius ratio.
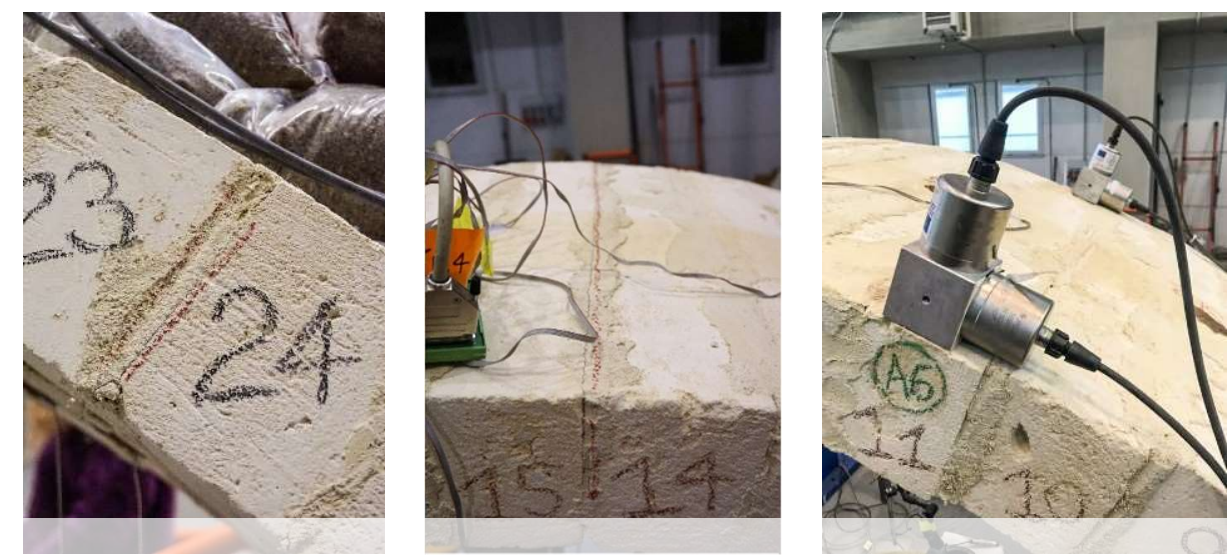

Figure 5: The three crack hinges

\subsection{Second phase: FRCM reinforced vault under eccentric concentrated load}

After the end of the first phase, the differential settlement of an abutment was blocked, the sandbags have been removed, and the crack hinges were filled by lime-cement mortar. Then,

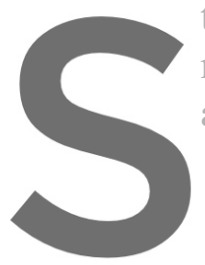
the extrados of the va

mortar embedding a bas average overall thickness
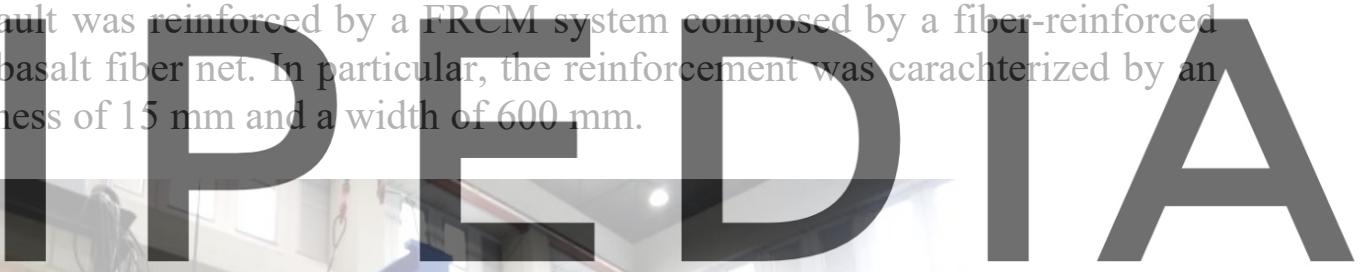

Register for free at https//www.scipedia.com to download the version without the watermark

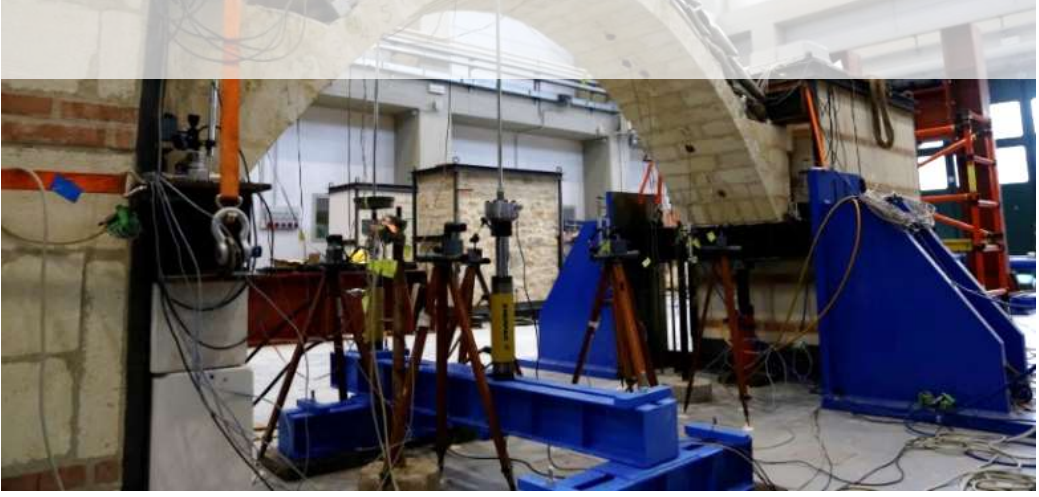

Figure 6: 2nd test. setup

After the curing time of the reinforcement, the sandbags were placed again on the extrados of the vault, and two "double-acting hydraulic return" jacks with maximum load capacity 98 $\mathrm{kN}$ were positioned symmetrically with respect of the two faces of the vault (front and back) on a rigid contrast beams system. On each jack a load cell with capacity of $100 \mathrm{kN}$ was 
mounted. This system (jacks and load cells) was connected by means of threaded rods to a rigid beam placed on the extrados of the vault in correspondence of voussoir 10 , at about $1 / 4$ of the span (Fig. 6). This way it was possible to apply an eccentric concentrate load on the reinforced masonry vault in order to evaluate the effectiveness of FRCM reinforcement.

The test was carried out in displacement control, by performing n. 8 loading-unloading cycles with progressively increasing displacements of the loaded voussoir. The low speed of the test was a key factor for actually realize a displacement control test. To this aim, an effective and constant monitoring of the oil pressure in the two hydraulic jacks was obtained by using a feedback system managed by a Labview software.
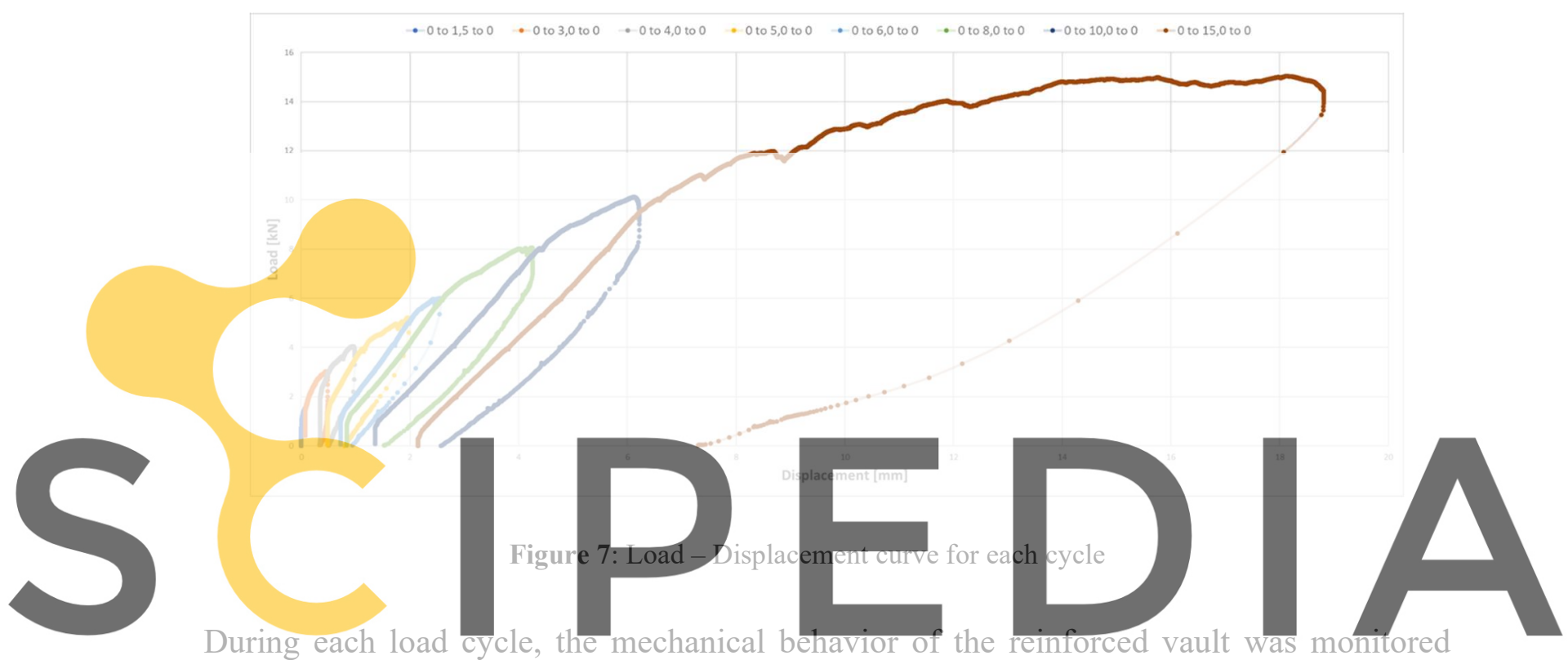

During each load cycle, the mechanical behavior of the reinforced vault was monitored through the described sensors: Moreover, at the end of each cycle a visual inspection was also

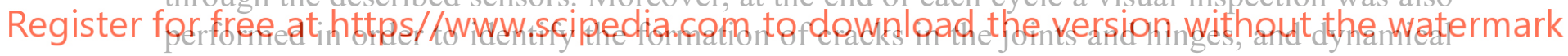
measurements were made through the accelerometers by exciting the structure with white noise.

Table 1: Second phase: main results for each loading-unloading cycle.

\begin{tabular}{cccc}
\hline Cycle & $\begin{array}{c}\text { Maximum Load } \\
{[\mathrm{kN}]}\end{array}$ & $\begin{array}{c}\text { Displacement at max load } \\
{[\mathrm{mm}]}\end{array}$ & $\begin{array}{c}\text { Residual displacement } \\
{[\mathrm{mm}]}\end{array}$ \\
\hline 1 & 1,5 & 0,00789 & 0,07708 \\
\hline 2 & 3 & 0,47135 & 0,34425 \\
\hline 3 & 4 & 0,94575 & 0,48135 \\
\hline 4 & 5 & 1,98235 & 0,24175 \\
\hline 5 & 6 & 2,47735 & 0,35400 \\
\hline 6 & 8 & 3,99235 & 0,87545 \\
\hline 7 & 10 & 6,13285 & 1,8675 \\
\hline 8 & 15 & 18,10135 & 6,2245 \\
\hline
\end{tabular}

The second experimental phase has been conducted until the vault was no longer capable 
to support additional load increase.

The overall experimental behavior of vault is summarized in Figure 7 by the superposition of the load-displacement curves obtained in the 8 loading-unloading cycles performed; in the diagram, the displacement refer to the load application point (voussoir 10) and it is obtained by averaging the measures provided by two potentiometric displacement transducers applied at the two sides of the loaded voussoir (see Sect. 3.1).

The curves in Figure 7 correspond to data in Table 1 that collects the main overall results obtained during the test: the value of maximum load $[\mathrm{kN}]$, the value of displacement at maximum load $[\mathrm{mm}]$ and the residual displacement $[\mathrm{mm}]$ at complete unloading for each cycle.

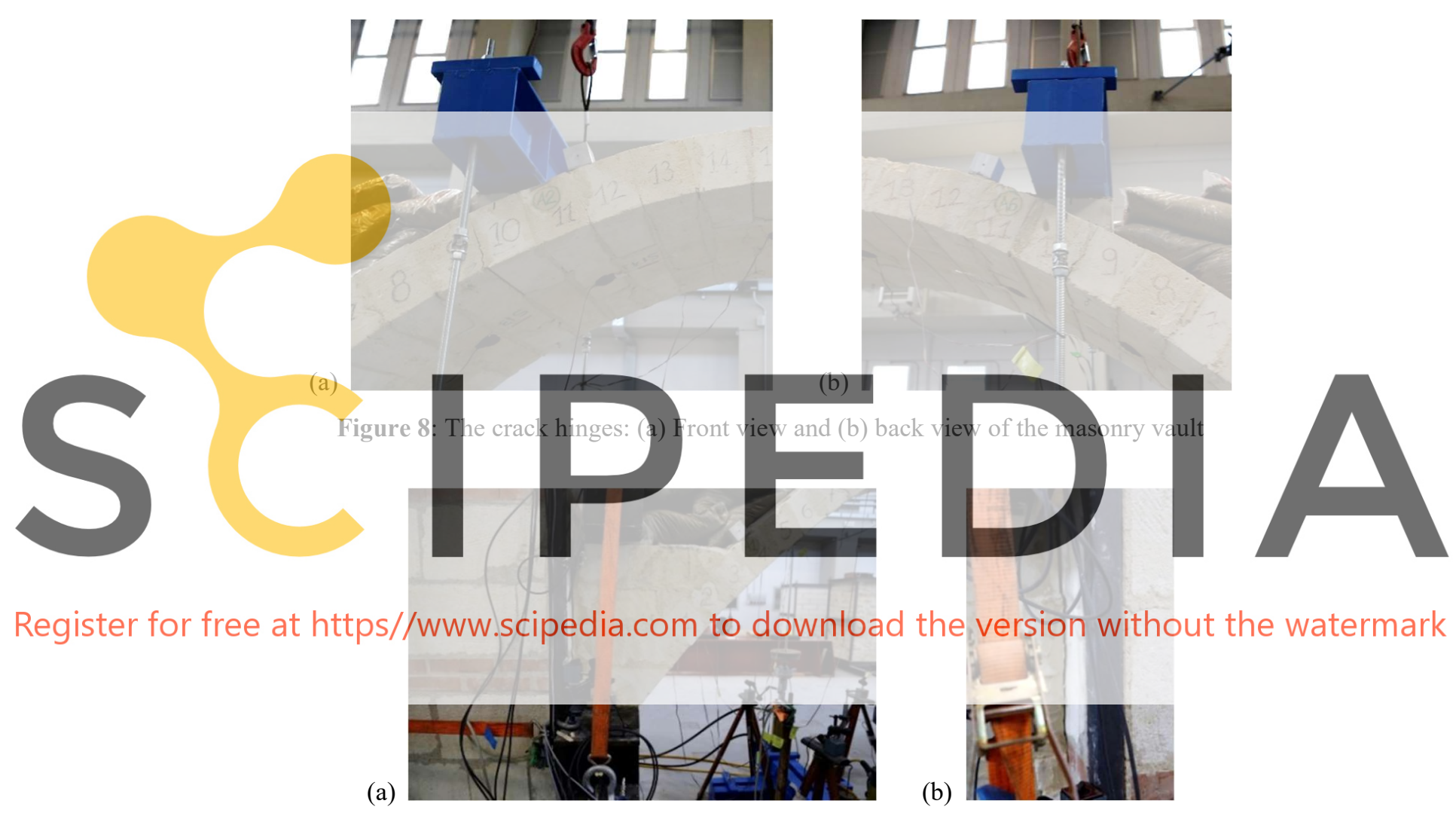

Figure 9: The crack hinges: (a) Front view and (b) back view of the masonry vault

As the load cycles progress, the first crack hinge has been observed at the intrados under the application point of the concentrated load, that is, between the voussoirs 9 and 10 (Fig. 8), during the fourth cycle (corresponding to a maximum load value of $5 \mathrm{kN}$ ).

No further cracks were observed in subsequent cycles, proving the effectiveness of the reinforcement system applied to the extrados of the vault.

The test was interrupted at the end of the eighth cycle (corresponds to a maximum load value of $15 \mathrm{kN}$ ) when a crack was observed between the vault and one of the lateral supports due to the rotation of the structure (Fig. 9). This rotation substantially prevented for further increase of the load. A reconstruction of the deformed profile of the intrados middle line for 
each load step, in the complete unloading state (permanent deformation) is showed in Fig. 10 through the data acquired by the six potentiometric displacement transducers and the two LVDT displacement transducers (see Sect. 3.1).

Further considerations will be possible when the large amount of collected data, including also dynamic measurements, will be completely reprocessed and examined.

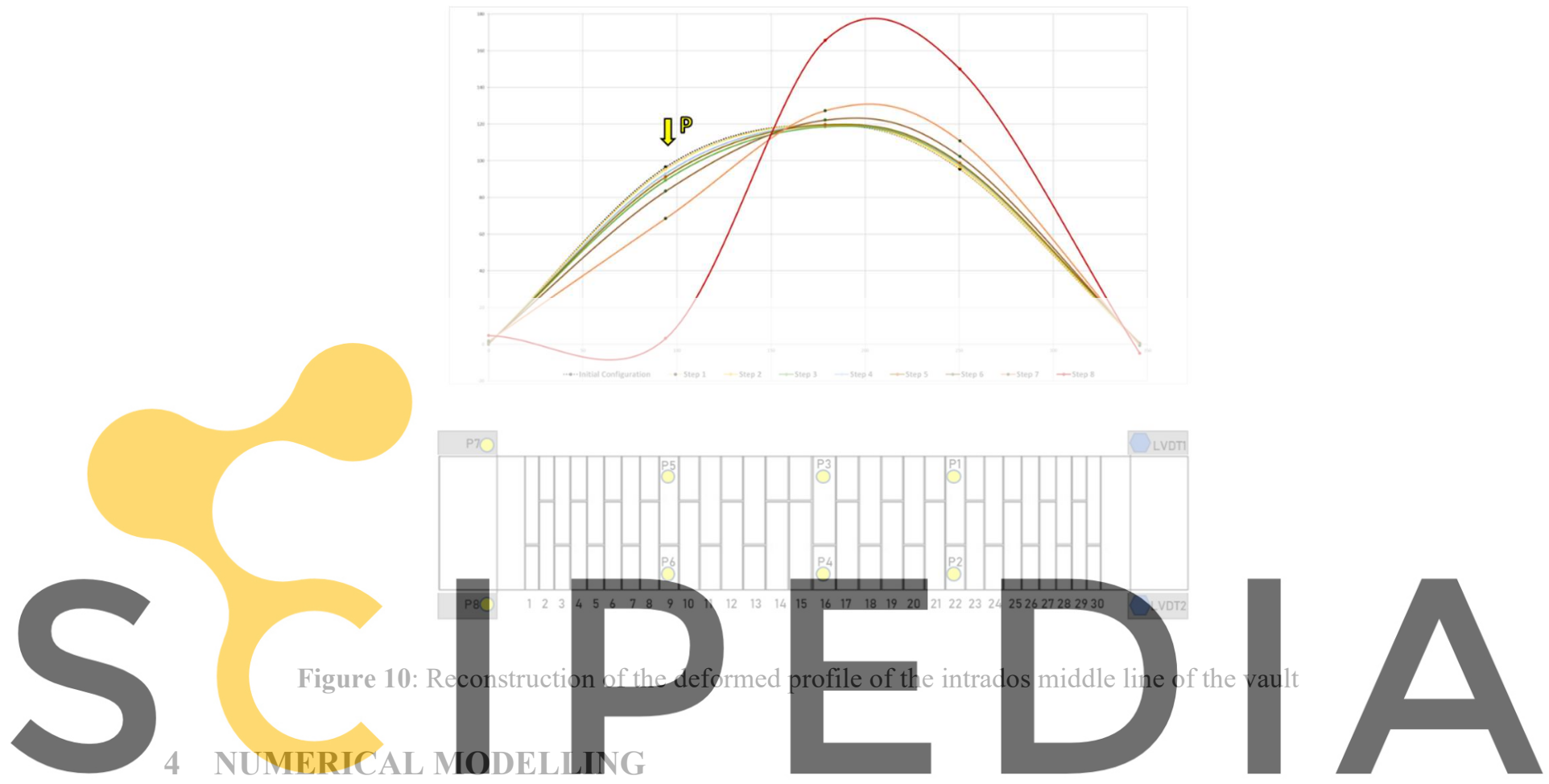

The outcomes regarding the second-phase of experimental campaign have been reproduced

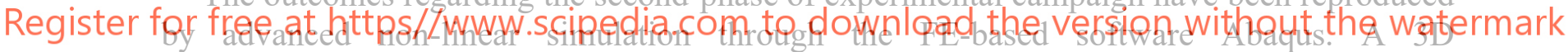

heterogeneous approach has been selected in order to model separately all of the components (stones, mortar joints, cementitious matrix, basalt fiber) of the reinforced vauit (Fig. 11). The non-linearities are assigned taking advantage of the Concrete Damage Plasticity model, available in the library of Abaqus and already applied with success to masonry structures [12]. Concrete damage plasticity is an isotropic elasto-plastic constitutive model with damage. The degradation of the elastic stiffness is determined by two variables of damage $\mathrm{dt}$ and $\mathrm{dc}$, functions of the plastic strains. Such variables vary between a value of 0 for the undamaged material and 1 for the material that has completely lost any stiffness. CDP allows the definition of a distinct behavior under tension and compression, respectively following an exponential softening and a parabolic softening. A 3D approach is preferred in order to ensure a better stability of the model and to avoid some inaccuracy associated to a 2D simplification of the problem. With this aim, only a portion of $100 \mathrm{~mm}$ along the thickness is modeled in order to reduce the computational burden. Non-linear properties are assigned to the stones of the vault, the mortar joints, the cementitious matrix and the fibers of the strengthening. These latter have been assigned of an elastic-fragile behavior with a negligible compressive strength in order to avoid unrealistic contribute to the global stiffness. 
Regarding the discretization, 8-noded solid bricks are used (Fig. 11). The joints present at least two elements in the thickness, whereas a rougher discretization is addressed to the tuff bricks. The matrix of the reinforcement is modeled as two different layers tied together with a global thickness of $15 \mathrm{~mm}$. The basalt fibers are idealized as 2-noded trusses and embedded in the middle of the cementitious matrix. Seven truss elements are introduced along the depth of $10 \mathrm{~mm}$ with an equivalent cross section, following a procedure already suggested in literature [13].

A tie connection is assumed among all the different elements, allowing the use of a differential discretization in the mortar and in the stones. However, in such a way, the detachment of the strengthening from the stone substrate is not modeled, because is considered a failure unlikely to occur in the case of FRCM strengthening. At the same time, also the slipping between the matrix and the fibers is not considered here. The geometrical model has been implemented on the deformed configuration obtained by the analysis reproducing the settlement phase and provided in [8]. Again, following the experimental procedure, the filling made of sandbags and the steel beams located at the spandrels are modeled directly as distributed and concentrated loads.

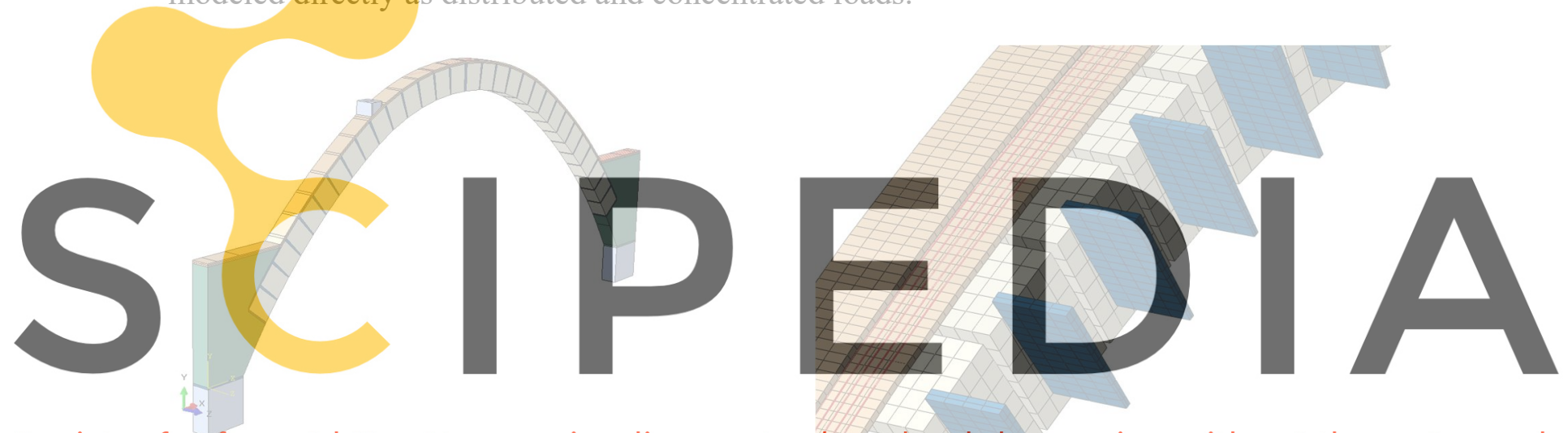

Register for free at https//www.scipedia.com to download the version without the watermark Figure 11: 3D Geometric model of the vault (Left); Mesh detail of each component (Right)

The non-linear analysis is conducted imposing an incremental displacement at the top of voussoir 10 and the first results of the numerical approach are here exposed. As expected, the first crack to occur is the one just under the concentrated load between voussoir 9-10, in correspondence of a load around $6 \mathrm{kN}$ (Fig. 12). Afterward, as noticeable from Figure 13, the load reaches a maximum value nearby $16 \mathrm{kN}$ in correspondence of $19 \mathrm{~mm}$.

Despite of an initial gap in the stiffness in the first stages of the analysis, the global behavior is well reproduced, being able to catch the final displacement and the peak load with adequate accuracy.

Regarding the damage pattern, the crack under the concentrated load and the rotation of the left spandrel are reproduced as well. Although, differently to the experimental observation, more damage occurred in two different location leading to a classic 4-hinges mechanism, even delayed by the presence of the reinforcement. A better fitting of the crack pattern with the experimental results may be the topic of future works by the Authors.

However, the micro-modeling approach succeeds in the simulation of the effectiveness of the FRCM strengthening on the global behavior of the vault, providing a numerical reference 
for the validation and the application of this technique even for the practitioners.
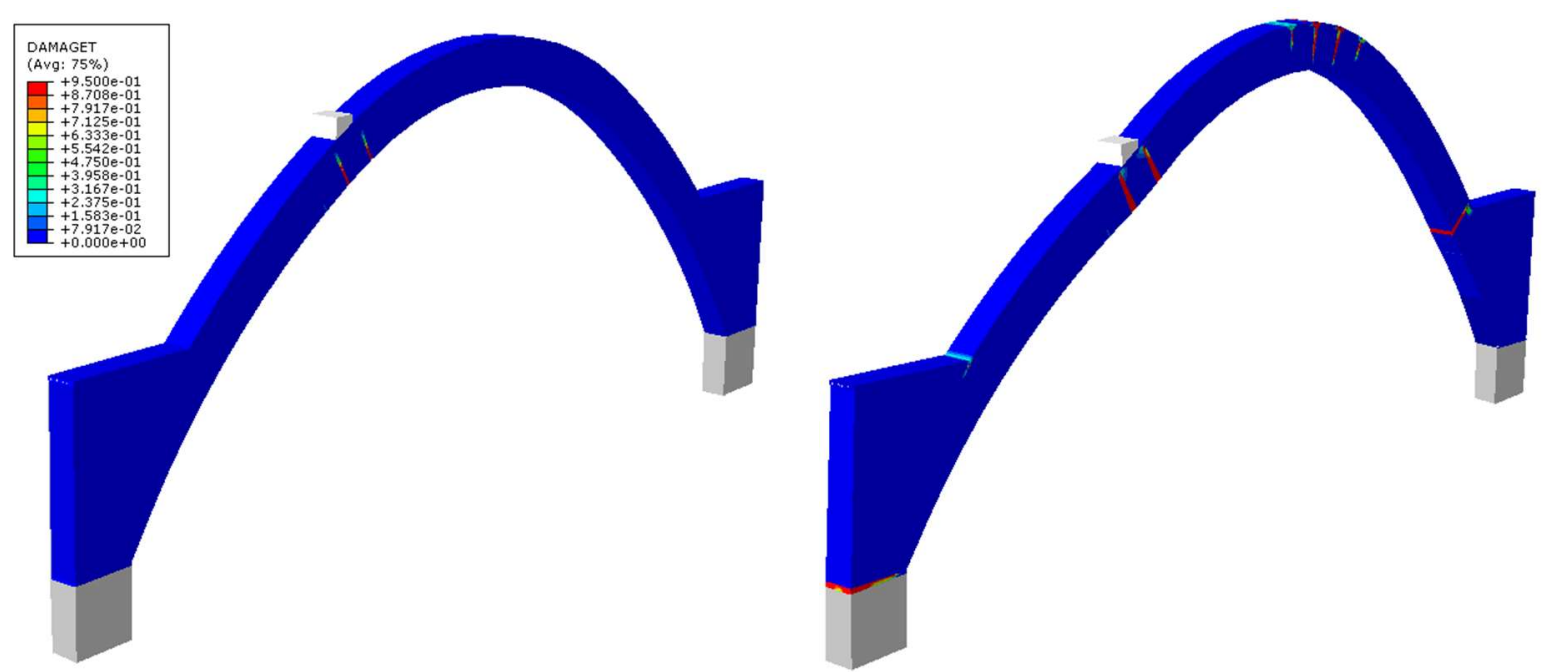

Figure 12: Damage configuration at the occurrence of the first crack (Left); Final damage crack pattern (Right)

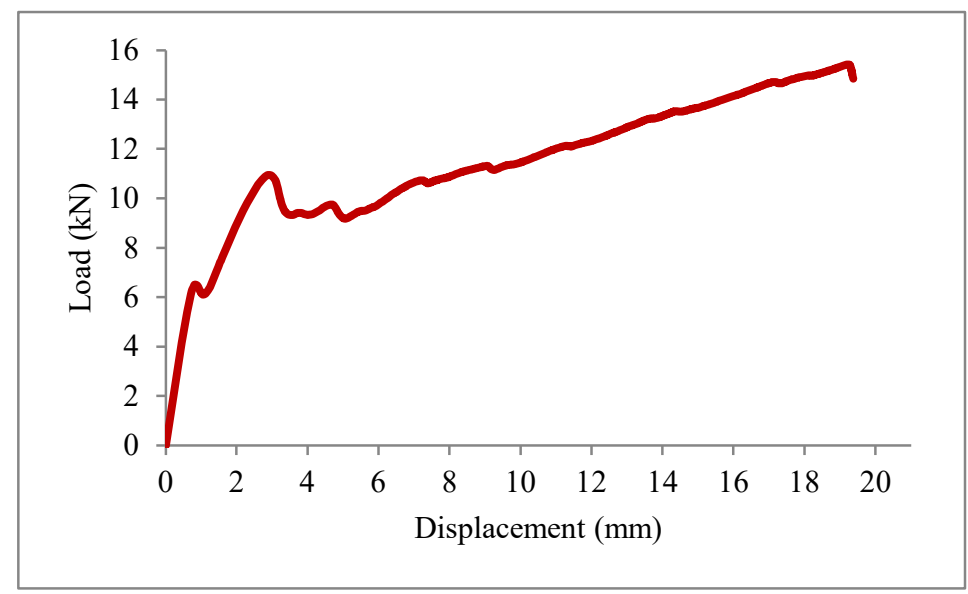

Figure 13: Load-displacement curve of the reinforced vault subjected to a concetrated load

\section{CONCLUSIONS}

The first result of an experimental and numerical analysis on a FRCM reinforced tuff masonry vault have been proposed. The full scale experiment performed give a broad overview on the complex structural response of the examined structures. The challenging problem of numerical modeling such a highly nonlinear problem has been faced by a micromodeling approach capable of reproducing the overall behaviour of the reinforced structure, although characterized by a relatively low level of complexity. This makes the propose approach interesting also for the employ in practical applications. 


\section{REFERENCES}

[1] Coccia, S. Di Carlo, F. and Rinaldi Z. Collapse displacements for a mechanism of spreading-induced supports in a masonry arch. Int. J. Adv. Struct. Eng. (2017) 7(3): 307320.

[2] Carozzi, F.G., Milani, G. and Poggi, C. Mechanical properties and numerical modeling of Fabric Reinforced Cementitious Matrix (FRCM) systems for strengthening of masonry structures. Compos. Struct. (2014) 107:711-725.

[3] Carozzi, F.G., Poggi, C., Bertolesi, E. and Milani, G. Ancient masonry arches and vaults strengthened with TRM, SRG and FRP composites: Numerical analyses. Compos. Struct. (2018) 187: 385-402.

[4] Valvona, F., Toti J., Gattulli, V. and Potenza, V. Effective seismic strengthening and monitoring of a masonry vault by using Glass Fiber Reinforced Cementitious Matrix with embedded Fiber Bragg Grating sensors. Compos. Part B-Eng. (2017) 113: 355-370.

[5] Carozzi, F.G., Poggi, C., Bertolesi, E. and Milani, G. Ancient masonry arches and vaults strengthened with TRM, SRG and FRP composites: Experimental evaluation. Compos. Struct. (2018) 187: 466-480.

[6] Castellano, A., Fraddosio, A., Scacco, J., Milani, G. and Piccioni, M.D. Dynamic response of FRCM reinforced masonry arches. Key Engineering Materials (2019) 817: 285-292.

[7] Scacco, J., Milani, G., Bove, M., Castellano, A., Fraddosio, A. and Piccioni, M.D. Experimental and numerical analysis of the effectiveness of FRCM strengthening on a parabolic tuff barrel vault. AIP Conference Proceedings (2019), 2186. DOI: $10.1063 / 1.5138011$

[8] Bove, M., Castellano, A., Fraddosio, A., Scacco, J., Milani, G. and Piccioni, M.D. Experimental and numerical analysis of FRCM strengthened parabolic tuff barrel vault. Key Eng. Mater. (2019) 817 KEM:213-220.

[9] De Santis, S., Roscini, F. and De Felice, G. Retrofitting masonry vaults with basalt textile reinforced mortar. Key Eng. Mater. (2017) 747: 250-257.

[10] Zampieri, P., Faleschini, F., Zanini, M.A. and Simoncello, N. Collapse mechanisms of masonry arches with settled springing. Eng. Struct. (2018) 156: 363-374.

[11] Ochsendorf, J. The masonry arch on spreading supports. Struct. Eng. (2006) 84(2): 2936.

[12] M. Valente and G. Milani, "Effects of Geometrical Features on the Seismic Response of Historical Masonry Towers," J. Earthq. Eng., vol. 00, no. 00, pp. 1-33, 2017.

[13] J. Scacco, B. Ghiassi, G. Milani, and P. B. Lourenço, "A fast modeling approach for numerical analysis of unreinforced and FRCM reinforced masonry walls under out-ofplane loading," Compos. Part B Eng., vol. 180, no. August 2019, p. 107553, 2020. 